\title{
23
}

\section{Local Knowledge and the Challenge of Regional Governance}

\author{
Paul Carter
}

This chapter considers the challenge of research capability building from the point of view of 'Ocean Connections', an interdisciplinary project convened as part of the Cooperative Research Network (CRN) program. Ocean Connections aimed to develop a new methodology of regional governance that allowed 'fragile environments' often lying outside governmental definition to be recognised and cared for. A threesided dialogue between Indigenous knowledge systems, eco-scientific environmentalism and urban design and creative arts discourses was brokered to offer planners and planning authorities a new way of understanding planned place making. This chapter offers a critical view of the terms 'building' and 'capability'. It describes an unfulfilled collaboration with the Northern Territory (NT) Government to establish a Strategic Planning Suite, discussing the place-making concepts and principles that informed its conceptualisation. Key concepts that we interpreted in new ways were local knowledge and regional governance. Proposing the idea of a 'creative region' that was self-organising and extra-territorial, we suggested this term contributed to a paradigm shift in contemporary master planning ideology. Such a shift, when it occurs, will question the identification of regional development with building and will associate capability with socially and environmentally sustaining attitudes of holding. 


\section{The Idea of Building Research Capability}

The CRN initiative underlying the present collection of essays had as its goal 'capability building'. The etymologies informing this phrase suggest a confusion of ideas. To be capable means to be receptive, to be able to grasp with two hands. The physical gesture associated with this idea, a cupping of hands, shapes a holding place-one that is roomy, ample and fitted for what will occupy it. The cultural (and geographical) analogue of capability is the harbour, a naturally capacious coastal zone whose human potential has been grasped. In this derivation of the word's meaning, a two-way moulding occurs. New research capability (in our context across the human, social and environmental sciences) reaches out to an environment in such a way that a new spaciousness, or room to live, is grasped or comprehended. Evidently, this poetic logic is different from the core associations of building, the act of house construction usually imagined as an act of resistance, enclosure and exclusion. To build new structures implies a natural deficiency or environmental hostility. Whether taken metaphorically or literally, it identifies being in the world with clearly circumscribed foundations and (logical) building blocks whose cumulative effect is to redefine the environment territorially and to assert control over the new divisions.

At the same time, particularly in a Northern Australian context, the notion of building capability translates into research programming a deeply entrenched historical and cultural identification of regional capability with development. Research that is useful to government, for example, will assist in clearing away obstacles to progress, define and consolidate structural and functional relations and, in general, provide the reason for planning. In this narrowed approach, better understandings of local environments and their cultures-which the bio- and ethno-sciences can respectively be expected to deliver-will improve regional capability. While regional capability is rarely defined, governments at least understand it quantitatively. Increased economic activity, improved social relations and opportunities and their mediation through improved communications enable politicians to reassure their constituencies that the region is, paradoxically, resilient to change and ready for it. However, the politicocultural logic informing this discourse depends on not questioning the building metaphor-the instrumentalist construction of knowledge in the interests of physically building the region is tacitly accepted by all parties. Other ways of conceiving the region-in terms, for example, 
of reciprocity, commensurability, integration and receptiveness-may be dismissed, even though these demonstrably lead to improved planning and public policy outcomes. In short, governments better equipped to build may have little grasp of, or capacity to deliver, good governance.

\section{The Strategic Planning Suite}

A significant illustration of this last statement was afforded by the Strategic Planning Suite, a joint proposal of the NT Government's Department of Infrastructure (formerly Department of Lands, Planning and Environment) and Charles Darwin University's Faculty of Law, Education, Business and Arts. Taken forward with support from the CRN research initiative Ocean Connections, the Suite was conceived as a new forum where planning priorities could be placed in a larger regional context. In bringing together representatives from different government departments charged with societal and infrastructural development and professional leaders in the study and exercise of alternative approaches to environmental management and governance, the expectation was that the rhetoric of region building could be loosened and diversified. In particular, by thinking between projects, the capability for growth and self-transformation already active in community and environment could be taken into account. In the context of the traditional neglect of expertise found in the broader place making, Indigenous and ecological knowledge communities, this would have represented an important innovation.

As I noted in my August 2013 vision statement:

Planning for development in the Northern Territory has traditionally been handled by the Department of Lands Planning and the Environment, and its predecessors, through a number of Divisions and also through other Northern Territory Government agencies and local government councils; more often than not in a sequential silo environment which is time-consuming, expensive and does not tend to capture more than the 'sum of the parts'. (Carter, 2013a, p. 2)

In promoting the Suite to the new CLP administration, we stated:

the object is to enable the Government to take advantage of the evolution occurring nationally and internationally from narrowlydefined master planning to holistic place making, from a narrowly functionalist practice of built environment planning and design to 
one that builds resilience and prosperity through the incorporation of environmental, cultural, social and creative resources into the planning and visioning process. (Carter, 2013a, p. 2)

The context of this offer was the growth in research capability occurring through the CRN programs. The purpose of the Ocean Connections program, for example, which I led, was to strengthen cross-disciplinary dialogue between the eco-sciences, Indigenous knowledge systems and sea/land management practices and environmental design, with a view to expanding our capability to understand better what might be meant by 'Northern Australia', what narratives and techniques might distinctively belong to its constitution and what environmental planning and management approaches might flow from these understandings. Translated into the language of planners, we urged 'holistic place making' against master planning. The point here, though, is that the proposed dialogue was across levels and disciplines. It sought to translate between place-based knowledges of different kinds and policy and planning. Our proposition was that the 'strange attractor' in this vertical translation between localised communities and their regional government was design, understood here as a multidisciplinary, bottom-up approach to place making. The object was not primarily to add to the quantity of information available, rather a qualitative shift was proposed, focused on recognising the capability of these different disciplines. What are the values to which they are receptive, and how, we asked, could these values inform 'the evolution of democratically-based governance systems' (Carter, 2013b, p. 8).

Ocean Connections proposed a connection between assumptions about spatial organisation and the premises of efficient administration. What, for example, is the relationship between the administrative region known as the NT and the domain referred to as 'Northern Australia'? What, further, is the operational value of either in the context of cultural histories that link parts of the northern coasts of Australia more strongly to what Frederickson and Walters (2001, p. ix) refer to as the 'Arafura region' than to the continental land mass of Australia itself? Frederickson and Walters (2001, p. ix) 'illustrate some of the many forms of cultural iteration objects undergo through their passage within and between cultures of the Arafura region'. This is a theme congenial to Ocean Connections, which, as described in Chapter 16 of this volume, aims to replace a 'continentalist' or 'dry thinking' approach to the historical imagination of places with one that is 'fluid', relational and interactive. In the present context, the 
concept of the 'Arafura region' not only displaces land-based definitions of region but redefines region itself as a network of displacements. As objects travel and acquire new meanings, so a region of new interests emerges. Translated into the rhetoric of regional development, Darwin, for example, begins to be the gateway or front door to Asia when its administrative and political cultures develop and exercise a capability for inter-regional exchange. Such a region has a different geography-its imaginary coastlines (see Carter, 2008a) are not hard and fast frontiers but irriguous, estuarine and receptive, like the harbour.

The proposed Strategic Planning Suite advocated the value of place making in informing government policy and planning. As a crossdepartment forum for integrated planning, it sought to integrate different understandings of place and to reflect these in the planning of planningattention would be given to the synergies of interest across different portfolios and, if possible, the traditional specialisations and exclusions of the different departmental interests would be relaxed and strategically blurred. The role of research, and of the research dialogue convened through the Suite, would be to provide expert understandings of places, their cultural, environmental and territorial characteristics and, no less important, new notions of place more adequate to the present globalised state of communications. In a way, the successful functioning of the Suite would create a new hybrid public region, one where administrative and research cultures could think holistically between projects. One of the functions of the Suite was to model:

future options for key locations, situations, and scenarios. In the first instance these options are strategic preferences, not prescriptive master plans. One of their key functions is to present complex datasets drawn from a variety of sources in visual, graphic and interactive forms that facilitate informed, engaged and creative discussion. (Carter, 2013b, p. 6)

\section{Local Knowledge}

One contribution of Ocean Connections to this discussion was to explore the knowledge peculiar to places. Local knowledge is conventionally defined oppositionally and defensively_long residence and an implicitly anti-developmentalist attitude are associated with it. For these reasons, local knowledge is, paradoxically, invaluable and discountable in the 
context of regional capability building-its authenticity is inversely proportional to its general utility (Carter, 2014, pp. 11-14). In the context of building capability, the object was not to propose and defend a new operational definition of place, but to show how variably places can be imagined, narrated and inhabited. An awareness of this in policy and planning circles would, presumably, improve government-auspiced exercises in place making. We approached this issue of definition through the lens of local knowledge-that is, the interdisciplinary domain of place-based experience and study jointly constituting 'sense of place'. This is not without difficulties:

Local or traditional ecological knowledge, for example, is very different from what planners understand local knowledge to mean in the context of 'place making'; in the biosciences, local knowledge is something different again, being, approximately, a local demonstration of general principles. (Carter, 2014, p. 2)

There are other vulnerabilities:

A detailed familiarity with one locality produces a unique experience of place; it is the basis of asserting that a locality has a character that is special. The value of the local resides in its particularity. There can be endless debate about the physical limits of the local but the human claim is clear: this place matters because it is different from anywhere else. Evidently, this claim is two-edged: local knowledge may enjoy a privileged authority but if it cannot generate senses of place that are applicable elsewhere, it is defenceless against 'general knowledge,' whose principles (whether ecological, political, cultural or strategic) are deemed valid precisely because they can apply anywhere. (Carter, 2014, p. 2)

A familiar paradox resulting from these vulnerabilities is what might be called a 'Xerox' approach to planned urban redevelopment (see Pratt, 2009). Invariably, master plans assert that one of their objectives is to build a sense of place. The zone earmarked for redevelopment or revitalisation (whether it is a downtown shopping mall, bayside suburb or an entirely new item of public/private infrastructure) will, it is asserted, enjoy or has enjoyed a unique cultural identity, one that the new plan aims to support. However, the terms of reference are entirely generichigh-quality urban design, heritage protection, public art and cultural activities are recommended without any indication that local knowledges might exist, making these measures of success supererogatory or, at worst, actively destructive. Given that in these schemes it usually falls to public 
art to give 'sense of place' values symbolic expression, it is even more astonishing to observe how public art strategies across all jurisdictions are essentially identical. Invariably, the public art will celebrate local stories and act as 'place makers' (or 'markers', as it is sometimes difficult to tell which is meant). But no generative power is ascribed to these symbolic narratives. What Lyotard (1984, p. 25) calls 'narrative knowledge' is firmly subordinated to the 'pragmatics of scientific knowledge', represented here by the efficiency of the master plan in producing a 'solution' legitimated not by any sensory resurgence ('sense of place') but by the simple operational criterion that the outcome corresponds to the plan.

To counter any devaluation of the local, Ocean Connections proposed a regional approach to local knowledge, one that defines the local non-territorially but in terms of common interests (Carter, 2014, p. 3). This had a number of aspects. It was strategic or pragmatic but also conceptual or political. With the geographical dispersion of communities along Australia's northern coastlines (and, more broadly, the Arafura region) in mind, I wrote:

In the context of the challenges to cultural and environmental biodiversity presented by development of all kinds, it is strategic that local knowledges make common cause. When a large scale mining project and its associated coastal infrastructure will affect a ribbon of communities across many hundreds of kilometres, a regional response, where different local knowledges are coordinated and integrated, carries more political weight than submissions from individual communities that are likely to differ in detail and in priorities. (Carter, 2014, p. 4)

I also made the point that:

when it is suggested that local knowledge can or should be 'scaled up' so that its principles can alter the way decisions are made at a regional level, it is often assumed that a head-to-head struggle with state or federal administrations is anticipated. However, the object of filtering different local knowledges for their common principles is not to create a case for greater powers being delegated to local or regional governments in their present form. The aim is to influence regional governance, that is, to redefine the way in which regions are conceptualized; when this happens, the change implied is not regulatory or fiscal but constitutional. (Carter, 2014, p. 4) 


\section{Creative Regions}

In a useful critique of Developing local knowledge, Davis indicated that the isolation I had attributed to place-based cultures and their knowledge systems might have been overdrawn. He cited a number of cases where local Aboriginal groups, whether clan based, language based or other community entities ... embed into various regional agreements and charters, statements regarding their local ecological knowledge and practices' (Davis, 2014, p. 6). These include the promotion of Indigenous 'water rights' in the Murray-Darling Basin through the formation of the Murray Lower Darling Rivers Indigenous Nations alliance, the establishment in the DubbaGa clan of the Wiradjuri people of 'networks among knowledge holders that transcend the specifics of a local place', the agreement between the Commonwealth Government's Wet Tropics Management Authority and the Aboriginal Forest Council to develop joint management strategies for 'a natural biological region, as well as a large and important Aboriginal cultural region', and the charters and statements of principles of the (former) Desert Knowledge Cooperative Research Centre (Alice Springs) (Davis, 2014, pp. $6-8)$. However, three of the four cases cited here accept terms of reference established by non-Indigenous legal or administrative/managerial fiat. This implies no criticism of the initiatives, which, as Davis (2014) emphasised, may stimulate the very debate about the commensurability of different local knowledges that I am keen to encourage. But the motivation of these regional agreements remains pragmatic — differences do not extend to a reevaluation of the region as such.

The 'creative region' advocated in Ocean Connections negotiates the subtle relationship between administrative and geographical cultures in a different way. While it is extra-territorial in the same sense that the Dubba-Ga knowledge holders live apart from the country from which their knowledge springs, its authority does not spring from actual or ancestral long residence in a particular place. Neither extra- nor intraterritorial, it is, rather, inter-territorial. The example is given in Ocean Connections of coastal zones. Although of defining importance in the colonial territorialisation of the word, they lack most of the formal properties of regions. As I noted:

Considered as a land/water ribbon, a linear zone stretching from Broome in the west to the Torres Strait in the east, Australia's northern coastline is a region between regions. It belongs neither to sea nor land: in the spatial discourse of the nation state it therefore 
counts for nothing. Even if the coast is where all the action is historically, commercially and strategically, no intermediate identity or distinctive topology is accorded it. (Carter, 2014, p. 5)

The argument for maintaining that the coast is a region is not, however, a purely cultural one. It reflects the broader human experience of living next to and with the sea. We have no difficulty in grasping the concept of a 'Mediterranean culture', where geographically scattered communities are connected by a shared maritime experience. A similar situation prevails across the Arafura and Timor seas, where Australian Aboriginal and Indonesian fishing communities live with the sea in similar ways. Ocean connections exist historically between Arnhem Land communities and Macassar. Many Macassan loanwords are found in northern coastal Aboriginal languages. A comparable cultural diaspora, differently motivated geo-politically, was promoted in the late eighteenth and early nineteenth centuries when British commercial interests mediated through the East India Company established trading headquarters in Calcutta, the Malacca Straits, Singapore and (intermittently and unsuccessfully) at Port Essington. The literature of coastal survey represents a continuum of style, content and interests reflective of a distinctively imperial interest, although in the aftermath of colonisation, this is marginalised. In any case, as a ribbon culture, the interests of the coast typically extend into and across the adjacent seas and, via rivers, inland as far as natural borders (catchments or escarpments) suggest (see Carter, 2015).

If, though, coasts can be regions, they immediately and dramatically bring into question the definition of region. Any region is a collection of parts, a multiplicity of shared interests. Its identity in difference is the key to its scale - constitutionally many, an aggregate of many localities, it yet possesses a recognisable identity. Conventionally, a region is a closed figure, a piece of the nation-state jigsaw. Alternatively, it is an international arrangement, an association of nations drawn together by geographical, economic or shared strategic interests. In every permutation, though, the problem of self-determination arises. The members of a regional arrangement do not meet on behalf of the region-the region is a rhetorical device that allows members to pursue their local interests collectively. Inside the nation-state, where the interests of local communities are supposed to map to the national interest, regional governance structures and mechanisms are correspondingly weak. In any case, regions are not established to operate inter-regionally, rather, they are constituted either top down, to mediate the devolution of centralised power, or bottom 
up, to find and protect common ground between local interests. In this doubly-disabling situation, the ribbon region of the coast is not an anomaly as it dramatises a political-administrative reality. Apart from the local communities that stake them out, regions have no powers, voices or distinctive responsibilities. The care they extend to the cultures and environments they share is not recognised in law or politically represented.

The consequences of this vacuum in cultural and environmental care are obvious. In our study region, the Arafura and Timor seas are treated as extensions of their bordering nation-states. No regional interest inhibits or benefits from the exploitation of their natural resources-which either occurs in 'international waters' or within the nation's 'territorial waters'. In general, the public and private promoters of large-scale natural resource projects (and the coastal infrastructure associated with servicing them) deal with objections to development on a case-by-case basis. Any resistance to the environmental and cultural impact of their operations is presumed to be local. The corollary-that local communities can be bought off if sufficient economic benefits can be shown locally-is also generally true. In this dialogue between inter/national and local, the regional has no voice. This can lead to a characteristic paradox. Where a proposed development is offshore, it is assumed that the developer is responsible to no local community-a local community's interests only come into play when the development of port facilities in their locality is mooted. In another version of this de-regionalisation of development, local communities are granted a voice solely on the basis that they are directly affected by the proposed change-a local community belonging to the same coastal region, but located a thousand kilometres away from the site of the contested development, would not be recognised as having a legitimate interest in minimising the impact of industrialisation on the local culture and environment.

This exclusion from governance issues of legitimate interest to local communities is not overcome by the kind of regional arrangements described by Davis (2014)—in these, a consolidation of common interests occurs but only on condition that the impact of these is experienced by each contributing community locally. The constitution of the region remains unchanged. In Ocean Connections, we proposed a different mechanism for the regionalisation of local interests. Invoking the idea of a 'creative region', one predicated on exchange across interests, borders and disciplines, we described a region that emerged through the conversation itself. The medium of exchange is narrative-the mediation 
of sense of place through symbolic forms that exercise the imagination and supplying the terms of reference for future innovation. Despite the unusual vocabulary deployed here (at least from a planning perspective), there is nothing strikingly novel about this proposal. It simply extends the 'language' of public art to every aspect of public domain planning. In this process, public art ceases to be a separate category of public infrastructure. Instead, new places are described, inhabited and cared for through a process of re-narrativisation. The inherited place myths are examined for their creative mechanisms-their explanations of cominginto-being — and the common ground found between them opens the way to forms of development that incorporate place memory into the placemaking design. In this way, objectives treated separately in master plans can be thought together-enhanced environmental integrity, heritage protection, social inclusiveness and so forth are secured through a prior constitution of the place as a 'creative region', one capable of generating its own best governance practices.

As we noted:

A recognition of the role poetic thinking plays in making sense of place redefines local knowledge as a mode of knowing that renders the abstract concrete. This aligns local knowledge with the material thinking characteristic of the creative arts. It is argued that key to building regional governance models responsive to local interests is the formation of creative communities. The region they envisage is archipelagic rather than territorialized; its governance is performative rather than procedural. (Carter, 2014, p. 1)

A 'creative region' is not simply a fragile environment, it embodies a different way of thinking about the biases of present governmental arrangements (and priorities) and provokes the possibility of alternative governance models. Such a region is essentially infinite, uncontainable, fluid and difficult to possess. Between territories, it defines the region of the 'commons'. Such a 'region' opens a new dialogue between placebased knowledges and the placeless axioms of regional planning. It is not amalgamated local knowledge-an up-scaling that simply defers the problem of authority, as any region can also be up-scaled without discernible impact on the abstraction of administrative categories and operational procedures - instead, it is a way of thinking about the different discourses of 'local knowledge' together through the conceptualisation of new places where, precisely, they talk to one another. 


\section{Master Planning}

The obvious situation where reconfigured local knowledge finds its application is in master planning. To redefine place making as the promotion of creative regions overcomes the technicist bias of current administrative specialisations, allowing (in principle) different departments and a widened community partnership to collaborate in an act of collective re-narrativisation. After uniplex and multiplex models of master planning urban design and infrastructure development, Healey (2005) discerned the emergence in the last couple of decades of a softened mode of planning - the one we have referred to as 'place making'. She characterised this as involving a new institutionalism, associated with environmentalism and driven by questions of sustainability, which emphasises the importance of a politics of place making, and which focuses on 'the active social construction of place-focused frameworks and efforts to cultivate strategic imagination through which key attributes of place can become identified and "owned" by many stakeholders, and "permanences" created in the "dynamic relational dialectics of urban life", (Healey, 2005, p. 261). In other words, the proposal to engage planners in cross-disciplinary dialogue about the establishment of integrated, regional templates for the identification, design and management of individual projects is not novel. It simply seeks to shift the responsibility for the ideation of new places from the abstract lexicon of planning to the concrete, symbolic narratives characteristic of creative communities and their regions.

One of the start-up research collaborations proposed for the Strategic Planning Suite was a review of the industrial development occurring at East Arm in Darwin Harbour. From a neo-liberalist or capitalistic point of view, the provision of new peri-urban infrastructure that enables the region to benefit from foreign investment is exemplary regional capacity building. However, the development had not been thought of regionallyeven its impact on the local environment had been confined to an arbitrary circuit of water in the immediate lee of the development. In the context of reconceptualising regions as archipelagoes of local knowledges, the object of the review was not to counter the localist bias of the East Arm cultural and environmental impact statements with, for example, a holistic description of the harbour as a whole. Such a description would certainly be an improvement on the fragmentary, project-by-project impact literature currently available, but it would not overcome the 
tendency to conceptualise the harbour as a territory for building. It would not measure important qualities of capaciousness, receptiveness and ocean connectedness that constitute it as both fragile and creative.

To bring these qualities into play would be, as I wrote of another project (a public spaces strategy for Victoria Harbour, Melbourne), to recognise the place

as a legacy of appearances and disappearances, in short, as a history of change. In this way attention shifts from static objects to mobile processes. It becomes possible to see the space as a dynamic, selfreinventing network of tracks, outlines, shadows, edges, sightlines and wakes- to see it as if it were reflected in the ever-changing face of the water. (Carter, 2008b, p. 186)

These insights might inform the cultural programming of the adjacent Darwin waterfront - they might be part of a discourse that reoriented Darwin to its maritime environment. To translate such poetic perspectives into a regional economy, it is necessary to relate the harbours to other harbours and recognise that they belong to a distinctive geographical taxonomy of 'half places' and doubled places. Defined by their receptiveness, harbours exist in relation to one another. As distinctive places of exchange, they model the potential of coastlines as a whole, to materialise the existence of a shared region of care. The cultural selfconfidence evident in this analysis translates into planning. It becomes possible to narrate major infrastructural developments contextually, for which the case of the proposed Glyde Point Industrial estate and the adjoining Muttamujuk Residential development was cited. In the context of a fly-in, fly-out employment pattern, with associated social isolation and communal stress, the insertion of new development opportunities into planning strategies that take account of regional care and governance expectations makes obvious sense.

Other agendas overtook the Strategic Planning Suite. Handed to Telstra, in return for the promotion of government programs, its link with the research sector was severed. In the wake of this, a pilot Australian Research Council Linkage-style research partnership was brokered with the NT Government's Department of Infrastructure and the Parks and Wildlife Commission. The invitation was to establish the brief for a full study into the options, timelines and costs for a complete 're-invigoration' of the Parks and Wildlife Commission, with a closer and more attractive alignment with eco-tourism and university-based research. 'Local knowledge'- 
defined in Ocean Connections as a multidisciplinary place-based discourse able to generate regional governance principles-was to underwrite the study. As we noted:

Successful place making builds on sound local knowledge. Local knowledge of critical value to PWCNT comes in three main forms: planning (awareness of local conditions), ecological sciences (understanding of biodiversity principles), Indigenous knowledge systems (traditional management of land and water). However, research shows that successful place making occurs when these three kinds of local knowledge are combined to produce place-based knowledge. Place based knowledge is the foundation of building a PWCNT vision that optimizes the individual visitor experience while communicating a Territory wide sense of place. It is the key to biodiversity conservation techniques that preserve local ecologies, at the same time understanding them as components of a regional mosaic of refuges. Place-based knowledge mediates between local knowledge and regional values. (Material Thinking, p. 4)

In the few days that we were permitted to work on this study, we produced impressive results. A new model of park management was proposed for investigation:

Networked (looped local knowledge is shared across the network to protect and promote regional values; qualitative data exchange and participatory management practices). The latter model factors in the value of the parks that exceeds the parts- the potential for the individual holdings to form an 'archipelago' of biodiverse 'refuges'. It also factors in the condition of the environment immediately adjoining key reserves. In this way it builds an awareness of the inter-connectedness of one of North Australia's primary assets and sources of social wellbeing. (Material Thinking, pp. 5-6)

A new interpretation strategy was proposed based on the 'Three circle park experience':

Multisensory experience of a natural environment (circle 1) is nested within narrative expectations of the place (the expectations the visitor brings, the memories they take away (circle 2). Both these experiences are themselves framed by the symbols (NT Tourism imagery, private transport operator imagery, internet information) used to communicate the park values (circle 3). The design, integration and interpretation of these different levels can transform the visitor experience: producing emotional identifications that foster further curiosity and interest, 
this investment in producing authentic stories about the place directly contributes to the challenge of maintaining biodiversity. (Material Thinking, p. 8)

In addition, and in consultation with local park rangers, we developed a new approach to the physical function and design of on-site interpretation facilities. Under the aegis of regionally appropriate and innovative design, the new 'meeting places' reconfigured the specialist knowledge from traditional and Western ecological sources as provocations to conversation and action incubating new creative communities. Perhaps it was a case of too much, too soon, as immediately after these first proposals were shared the study was closed down. In the absence of any further communication, the reasons behind the Parks and Wildlife Commission's decision to abort the partnership remain a matter of speculation. In a way, the curtailment of this attempt to broaden the definition of region-based research capability building to incorporate creative place making, management and governance practices already resident in the community illustrates the challenge that still remains. A new dialogue between government and research sectors is inevitable, but its cultivation will evidently depend on a careful mix of good communication, crosssectoral trust and bold leadership.

\section{References}

Carter, P. (2008a). Dark with excess of bright: Mapping the coastlines of knowledge. In P. Carter, Dark writing, geography, performance, design (pp. 49-78). Honolulu, HI: University of Hawai'i Press.

Carter, P. (2008b). Solutions: Storyboarding a Humid zone. In P. Carter, Dark writing, geography, performance, design (pp. 173-202). Honolulu, HI: University of Hawai i Press.

Carter, P. (2013a, 23 April). Ocean Connections, a new region leadership, care and design project, located at The Northern Institute, Charles Darwin University, 2013-2015. Paper delivered at Northern Institute, Charles Darwin University (pp. 1-23). Obtainable on request from author.

Carter, P. (2013b, 6 August). Proposal to develop a Strategic Planning Suite. Australia: Land Development Division, Department of Lands, Planning and the Environment, Northern Territory Government and Charles Darwin University. Obtainable on request from author. 
Carter, P. (2014, March). Developing local knowledge: What translates? Paper delivered at Northern Institute, Charles Darwin University (pp. 1-32). Obtainable on request from author.

Carter, P. (2015). Australindia: The geography of imperial desire. Postcolonial Studies, 18(2), 1-12.

Davis, M. (2014, October). Critical response to Paul Carter 'Developing Local Knowledge: What translates?'. Paper commissioned by Paul Carter on behalf of 'Ocean Connections' project. Obtainable on request from author.

Frederickson, C. \& Walters, I. (2001). Introduction. In C. Frederickson \& I. Walters (Eds), Altered states: Material culture transformations in the Arafura Region (pp. i-xii). Darwin, NT: Northern Territory University Press.

Healey, P. (2005). Planning in relational space and time: Responding to new urban realities. In A. Ballantyne (Ed.), Architecture theory: A reader in philosophy and culture (pp. 259-271). London, England: Continuum.

Lyotard, Jean-François. (1984). The postmodern condition: A report on knowledge (Geoffrey Bennington and Brian Massumi trans.). Manchester: Manchester University Press.

Material Thinking. (2014, December). Parks and Wildlife Commission of the Northern Territory: An integrated management vision based on a review and assessment of PWCNT's two exemplar parks: Litchfield National Park and Casuarina Coastal Reserve. Obtainable on request from author.

Pratt, A. (2009). Policy transfer and the field of the culture and CCIs: What can be learned from Europe? In L. Kong \& J. O'Conner (Eds), Creative economics, creative cities. Dordrecht, The Netherlands: Springer. 
This text is taken from Leading from the North: Rethinking Northern Australia Development, edited by Ruth Wallace, Sharon Harwood, Rolf Gerritsen, Bruce Prideaux, Tom Brewer, Linda Rosenman and Allan Dale, published 2021 by ANU Press, The Australian National University, Canberra, Australia. 